\title{
Surface structure, pore characteristics and mechanical response of aluminum foam processed by wire-EDM and milling
}

\author{
Nikolaos Michailidis ${ }^{1}$, Andreas Klink ${ }^{2}$, Emmanouil Smyrnaios ${ }^{1}$, Marcel Olivier ${ }^{2}$, Nearchos \\ Baklatzoglou ${ }^{1}$, Lukas Welschof ${ }^{2}$, Fani Stergioudi ${ }^{1, *}$ \\ ${ }^{1}$ Physical metallurgy Laboratory, Dept. of Mechanical Engineering, School of Engineering, Aristotle \\ University of Thessaloniki, 54124 Thessaloniki, Greece \\ ${ }^{2}$ Laboratory for Machine Tools and Production Engineering (WZL), RWTH Aachen University, D- \\ 52074 Aachen, Germany
}

\begin{abstract}
Material removal processes like milling, leave only a small process window to minimally distort the surface of Aluminum foams. Wire-EDM arises as a suitable alternative. Closed-cell aluminum foams were produced and processed at various conditions through wire-EDM to investigate their effect on the foams' surface integrity. Microstructural analysis, porosity assessment and mechanical testing were employed to evaluate the footprint of the manufacturing process. Depending on the process parameters and especially on the working fluid, severe surface and pores damage may occur, affecting the mechanical response under quasistatic and high-velocity impact loads. A process optimization loop offered a distortion-free surface.
\end{abstract}

\section{Introduction}

The restricted machinability of porous materials compared to bulk ones, due to the development of intense dynamic loads during cutting, worsens significantly the produced surface quality. The latter is characterized by burrs and distorted regions which increase the risk for a sudden failure by the operational loads [1-3]. As a consequence the potential to produce well-formed porous compounds is a task of high industrial interest. Several manufacturing processes were proposed in literature for porous metals, such as milling, circular saw cutting, water jet cutting, plasma, laser etc. [4-8]. The Wire Electrical Discharge Machining (wEDM) is the machining process during which material is eroded by series of controlled sparks between electrode and the workpiece. Wire electro-discharge machining (wEDM) appears as an attractive alternative solution to counteract many of the known problems in the machining process of porous metals $[9,10]$. During wire-EDM of bulk metals micro pores in material can possibly be created. Additionally a layer of melted and resolidified material called recast can also be found on the surface after wire-EDM. However, the influence of porous metals on the machining performance of wire- EDM is unclear.

* Corresponding author: fstergio@auth.gr 
In this work, milling and wire electro-discharge machining of porous aluminium were applied. For assessing the effectiveness of each manufacturing process, the mechanical response during quasi-static compression and high-velocity impact loading of porous aluminium was investigated. Moreover, macro- and micro-structural characterization of the resulted surfaces after the conduct of each individual manufacturing process facilitate to determine the optimum method for material removal and interpret the experimental results during quasi-static compression and high-velocity impact loading.

\section{Materials and methods}

\subsection{Porous Al production and characteristics}

The porous $\mathrm{Al}$ was fabricated by a casting process. Calcium (Ca) was admixed with molten aluminum at $680{ }^{\circ} \mathrm{C}$ and stirred for $6 \mathrm{~min}$ (to enhance the viscosity of the melt). The foaming agent used was $2 \mathrm{wt} \% \mathrm{TiH}_{2}$ which was added in the melted aluminum at 660 $680^{\circ} \mathrm{C}$ [11]. The produced cast Al-foam block, having a porosity of $80 \%$, was sliced into flat plates of $30 \mathrm{~mm}$ thicknesses.

\subsection{Wire-EDM machining analysis}

The experimental study on the machinability of the Al-foams by Wire-EDM and the resulting surface integrity focused both on the usage of standard water-based and in addition $\mathrm{CH}$-based dielectrics. Basic experiments were executed on machining of simple prismatic workpieces allowing the detailed study on achievable cutting rates for main and trim cuts as well as analyzing and optimizing process conditions from discharge energy and therefore machine generator point of view [12]. In addition, for the further mechanical testing, cylindrical parts were machined by a finally derived one-cut-strategy with generator conditions determined by the former main cut analysis. From technical point of view, foam parts in practical application would also normally be cut favourably only with a one-cutstrategy as clamping of these parts - especially inner parts like the cylinders - is very complicated. Additional clamping changes and re-clamping for the application of trim cuts is very critical due to the foam structure and resulting small supporting areas.

The machine tools engaged in the investigations were GFMS Cut 2000 X Oiltech $(\mathrm{CH}-$ based dielectric: oelheld IonoFil 80) and Cut S350 (water-based dielectric). For the discharge energy analysis, the actual current and voltage conditions were measured with an oscilloscope Tektronix DPO 7104c and further processed by a self-built Matlab script. For the water-based dielectric a standard technology for the machining of aluminium was available including main and 3 consecutive trim cuts for best surface qualities.

As electrode, a standard brass wire (Bedra BercoCut Pro) with a diameter of $0.25 \mathrm{~mm}$ was used. For the $\mathrm{CH}$-based dielectric only a standard steel technology was available including main and two trim cuts. As electrode, also a standard brass wire (Bedra BercoCut Pro) with a diameter of $0.2 \mathrm{~mm}$ was used.

Based on the given generator settings the machining parameters "I", "P" and "S $\mathrm{S}_{\text {soll }}$ " were varied to analyze their capability to improve the cutting conditions in terms of an increased cutting rate as well as stable machining with a sufficient working gap to avoid wire breakages. I determines the discharge duration $t_{e}$ and the discharge current $\mathrm{i}_{\mathrm{e}}$. $\mathrm{P}$ determines the pulse interval time $t_{0}$. A higher value increases the discharge frequency by reducing the interval time. $S_{\text {soll }}$ determines the servo control feed system. A high value sets a high average gap voltage achieved by a control tendency to have a bigger wire distance. A small value sets a more aggressive machining condition with small gaps and therefore small 
average gap voltages [13]. For both fluids, this value had to be increased from standard settings to reach stable machining conditions for the Al-foam.

All the experiments were conducted while the aluminum foam was clamped in one position (see Figure 1). The large clamping area prevented the specimen from being damaged by mechanical forces and ensured a secure fit and good electrical connectivity. Small specimens were prepared with surfaces revealing the EDMed cell connectors incorporating the different discharge conditions for further metallurgical analysis [14]. The upper wire guidance system was positioned $2 \mathrm{~mm}$ above the workpiece.
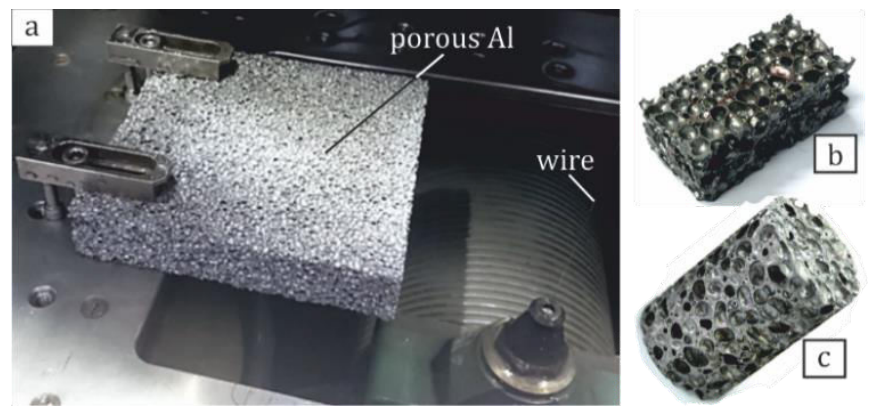

Fig. 1. (a) Areal clamping of raw Al-foam plates and machining of: (b) prismatic parts for basic testing and analysis and (c) cylindrical samples for mechanical testing.

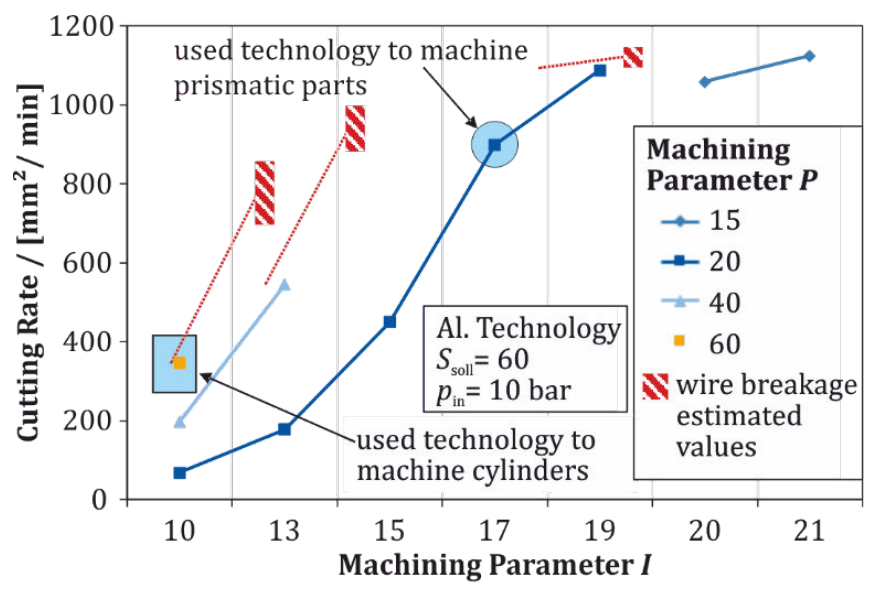

\begin{tabular}{|c|c|c|c|c|c|c|c|}
\hline $\begin{array}{c}\text { Machine } \\
\text { Parameter } \\
\text { I }\end{array}$ & $\begin{array}{c}\text { Open } \\
\text { Circuit } \\
\text { Voltage } \\
\text { ûi [V] }\end{array}$ & $\begin{array}{c}\text { Average } \\
\text { Discharge } \\
\text { Voltage } \\
\overline{u i}[V]\end{array}$ & $\begin{array}{c}\text { Max. } \\
\text { Discharge } \\
\text { Current } \\
\text { imax [A] }\end{array}$ & $\begin{array}{c}\text { Average } \\
\text { Discharge } \\
\text { Current } \\
\text { ie }[\mathrm{A}]\end{array}$ & $\begin{array}{c}\text { Discharge } \\
\text { Duration } \\
\text { te }[\mu \mathrm{s}]\end{array}$ & $\begin{array}{l}\text { Discharge } \\
\text { Energy } \\
\text { we [mJ] }\end{array}$ & $\begin{array}{l}\text { Lateral } \\
\text { Gap Width } \\
\text { sL }[\mu \mathrm{m}]\end{array}$ \\
\hline 10 & 80 & 23,4 & 121,5 & 74,3 & 0,76 & 1,54 & 25 \\
\hline 13 & 80 & 25,4 & 208,2 & 125,2 & 1,0 & 4,2 & 35 \\
\hline 15 & 80 & 30,6 & 329,8 & 197,6 & 1,13 & 9,1 & $=$ \\
\hline 17 & 80 & 39,3 & 467,6 & 284,0 & 1,5 & 22,3 & "- \\
\hline 19 & 80 & 44,9 & 563,3 & 346,4 & 1,9 & 37,8 & - \\
\hline 20 & 80 & 47,3 & 646,8 & 400,2 & 2,2 & 52,6 & - \\
\hline 21 & 80 & 46,9 & 778,6 & 480,3 & 2,3 & 66,2 & - \\
\hline
\end{tabular}

\begin{tabular}{|c|}
\hline $\mathrm{T}_{0}$ \\
\hline
\end{tabular}

Fig. 2. Achieved cutting rates during main cut experiments in water-based dielectric. 
The achieved cutting rates during main cut machining in the water-based dielectric as function of the parameter I are shown in Figure 2. The highest cutting rates in the range of above $900 \mathrm{~mm}^{2} / \mathrm{min}$ can be reached with I-values higher than 17 and moderate P-values about 15-20. For analyzing this discharge regime prismatic parts were machined with an Ivalue of 17 reaching a cutting rate of $900 \mathrm{~mm}^{2} / \mathrm{min}$.

To increase cutting rates for lower I-values, the discharge frequency could be increased by increasing the P-values from 20 to 40 or even 60 but with an increasing risk for wire breakages due to a too aggressive process. The cylindrical parts were machined with this technology regime resulting in average cutting rates between 300 and $400 \mathrm{~mm}^{2} / \mathrm{min}$ with a variation of the P-values between 45 and 60 . For the machining in the $\mathrm{CH}$-based dielectric average cutting rates in the range of $100 \mathrm{~mm}^{2} / \mathrm{min}$ could be achieved for the main cut and according generator specific settings of $\mathrm{I}, \mathrm{P}$ and $\mathrm{S}_{\text {soll }}$.

To get a more generic and physical understanding on the energy dissipation into the surface of the Al-foam during the Wire-EDM process the according discharge regimes based on the given machining parameters were analyzed in detail via assessment of the current and voltage signals gathered by the oscilloscope (see table in Figure 2 and Table 1).

The cylinders machined in the water-based dielectric with $\left(I=10, P=45-60, S_{\text {soll }}=60\right)$ were processed with an average discharge energy of $\mathrm{W}_{\mathrm{e}}=1.5 \mathrm{~mJ}$ and an average discharge duration of $\mathrm{t}_{\mathrm{e}}=0.8 \mu \mathrm{s}$. This can directly be compared to the cylinders machined in $\mathrm{CH}$ based dielectric as the average discharge energy of $\mathrm{W}_{\mathrm{e}}=1.8 \mathrm{~mJ}$ and the average discharge duration of $\mathrm{t}_{\mathrm{e}}=0.6 \mu \mathrm{s}$ are in the same order of magnitude.

A much higher energy level can be found during the main cut of the prismatic parts $\left(\mathrm{I}=17, \mathrm{P}=20, \mathrm{~S}_{\text {soll }}=60\right)$ in the water-based dielectric. These were processed with an average discharge energy of $\mathrm{W}_{\mathrm{e}}=22 \mathrm{~mJ}$ and an average discharge duration of $\mathrm{t}_{\mathrm{e}}=1.5 \mu \mathrm{s}$. A much lower energy level can be found during the second trim cut of the prismatic parts in the $\mathrm{CH}$-based dielectric. These were processed with an average discharge energy of only $\mathrm{W}_{\mathrm{e}}=0.3 \mathrm{~mJ}$ and an average discharge duration of $\mathrm{t}_{\mathrm{e}}=0.2 \mu \mathrm{s}$.

Table 1. Machining conditions for the main and trim cuts in $\mathrm{CH}$-based dielectric.

\begin{tabular}{|c|c|c|c|c|c|c|}
\hline & $\begin{array}{c}\text { Open } \\
\text { Circuit } \\
\text { Voltage } \\
\text { uî }[\mathrm{V}]\end{array}$ & $\begin{array}{c}\text { Average } \\
\text { Discharge } \\
\text { Voltage } \\
\overline{u i} \text { [V] }\end{array}$ & $\begin{array}{c}\text { Maximal } \\
\text { Discharge } \\
\text { Current } \\
\text { imax }[\mathrm{A}]\end{array}$ & $\begin{array}{c}\text { Average } \\
\text { Discharge } \\
\text { Current } \\
\text { ie }[\mathrm{A}]\end{array}$ & $\begin{array}{c}\text { Discharge } \\
\text { Duration } \\
\text { te }[\mu \mathrm{s}]\end{array}$ & $\begin{array}{c}\text { Discharge } \\
\text { Energy } \\
\text { we [mJ] }\end{array}$ \\
\hline Main Cut & 110 & 32.1 & 149.2 & 97.9 & 0.57 & 1.79 \\
\hline First Trim Cut & 110 & 18.3 & 99.0 & 66.0 & 0.465 & 0.56 \\
\hline Second Trim Cut & 250 & 69.3 & 40.9 & 21.9 & 0.19 & 0.29 \\
\hline
\end{tabular}

\section{Results and discussion}

\subsection{Macro- and micro-structural characterization of the porous Al}

Figure 3 presents a macro and meso-scale analysis of the cylindrical porous samples produced by milling, CH-dielectric wire-EDM (wEDM-CH), and water-dielectric wireEDM (wEDM-Water). Characteristic pictures of the samples shown at the top of the figure reveal a severely corroded sample in the case of wEDM-Water, as reflected by the thinning of the foam cells yielding in many cases in the opening of the cells. The wEDM-CH seems to have a minimum corrosion impact on the sample. In both cases, the surface quality of the cut surfaces looks very good, with the wEDM-Water porous samples having a higher roughness. The milled cylindrical samples, although they are corrosion-free, they are 


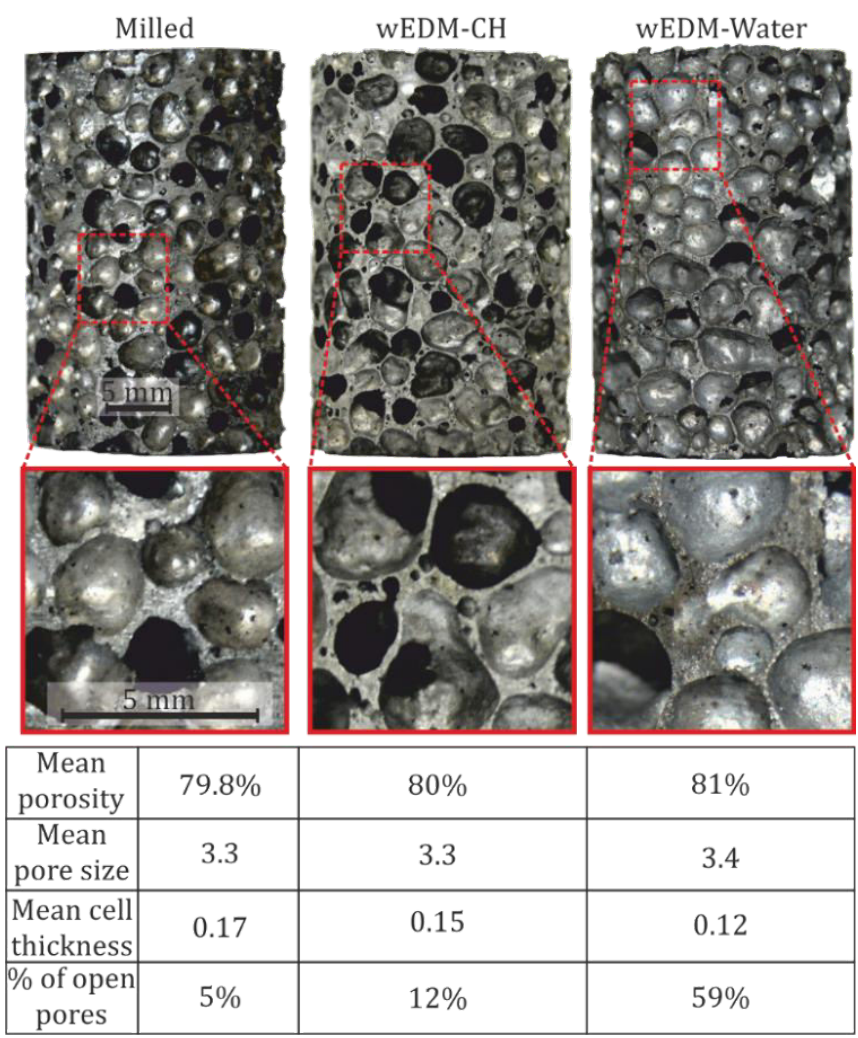

Fig. 3. Macro- and meso-scale characteristics of the differently cut porous samples.

slightly distorted on their surface, due to the cutting forces. The cutting conditions applied, were selected based on the FEM model of the milling process to minimize cell and surface distortion found in [2]. The table at the bottom of the figure summarizes the porous characteristics for the three cases, after image analysis. It is clearly presented that the wEDM-Water severely affects the cell thickness, even leading to breakages of the cell integrity, by creating openings of the cells, which amount to the $59 \%$ of the total cell lying at the cylinder periphery. This percentage of the open cells starts at $5 \%$ for the milled sample and reaches $12 \%$ in the case of wEDM-CH.

Trying to interpret in micro-scale the effect of the dielectric medium on the wire-EDM of porous aluminum, the microstructure of the samples was investigated at regions close to the core and close to the cut surface. Figure 4 shows characteristic XRD results (Figure 4a) and a SEM image (Figure 4b) corresponding to the "as-produced" porous microstructure at its core. Aluminum reacts with $\mathrm{Al}_{4} \mathrm{Ca}$ phase and produces an eutectic structure (laminate morphology), as shown in the SEM image (Figure 4b). The white areas, which represent the elongated morphology, correspond to the $\mathrm{Al}_{3} \mathrm{Fe}_{4}$ phase. The $\mathrm{Al}_{3} \mathrm{Fe}_{4}$ phase has an orthorhombic crystal structure (meaning that it has one lattice vector much larger than the other two), which fits with the elongated morphology observed in the SEM image. Gray phases correspond to $\mathrm{Al}_{\mathrm{x}} \mathrm{Ti}_{\mathrm{y}}$ phases that present either cubic or hexagonal crystal structure. There is no apparent texturing in the aluminum phase, however, a slight shift observed only in the minor reflections peak of aluminum (not in the largest peak) is ascribed possibly to small amounts of silicon. Form the XRD results it is deduced that the foam is oxide-free but certainly presents enough iron phases possibly originated from local melting of the agitator or the tank during the foam production process. 

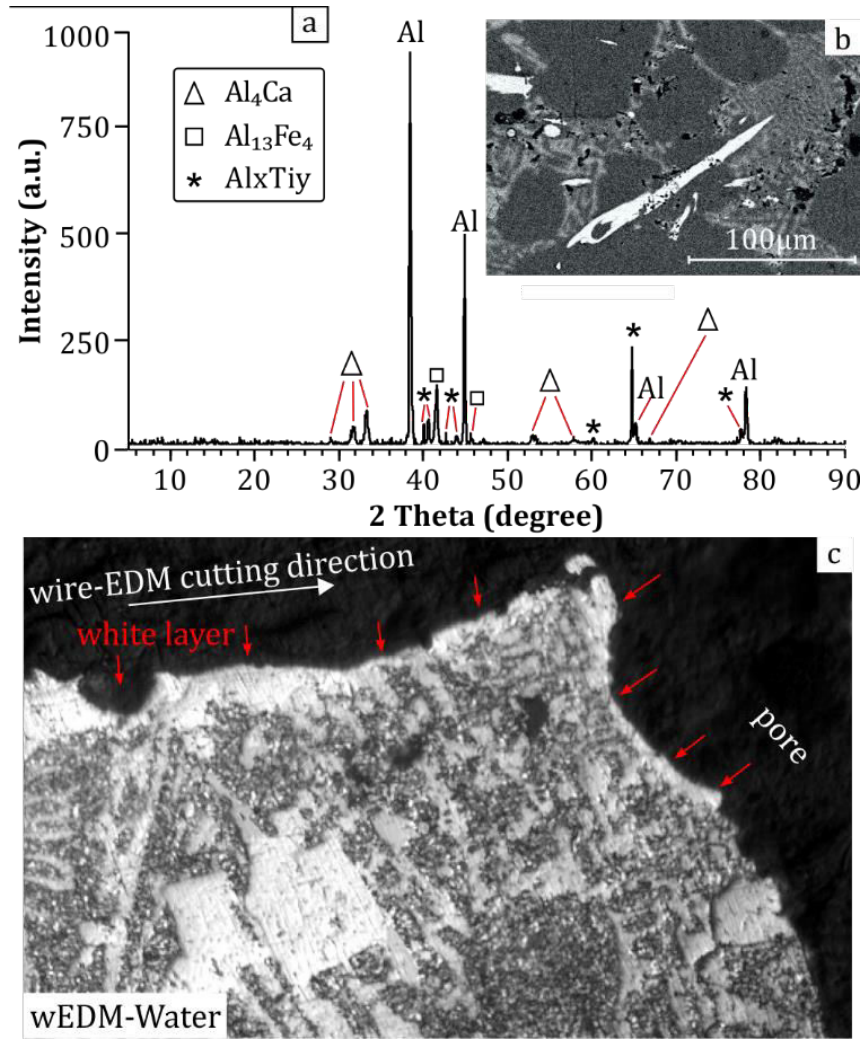

Fig. 4. Characterization of the "as-produced" foam microstructure by (a) XRD and SEM analysis. (c) White layer formation in wEDM-Water sample.

After a thorough investigation in optical and scanning electron microscopes, severe surface damages were evident only in the cases of wEDM-Water and a representative optical microscope image is presented in Figure 4c. The formation of a 5-20 $\mu \mathrm{m}$ thick white layer on the cutting path as well as at its proximity is clearly shown. Even in the neighborhooding pore, close to the wire path, there is a white layer formed on the surface.

\subsection{Mechanical testing}

To realize the effect of the cutting process on the mechanical response of the differently cut porous Al, quasi-static compression tests were performed. Figure 5 shows the engineering stress - strain response of the three examined cases together with characteristic images of samples at various strain levels (A, B, and C, as indicated in the diagram of the figure. In terms of overall performance (maximum stress and plateau stress), both milled and wEDM-CH samples performed quite well, with the wEDM-Water sample exhibiting the worst stress-strain response. An explanation of the mechanical response is coming from the pictures captured at various strain levels, which in the case of wEDM-Water is accompanied by material delamination. This is also reflected in the stiffness of the porous samples, where the wEDM-Water $(0.4 \mathrm{GPa})$ sample has more than 3 times lower stiffness than the milled one $(1.3 \mathrm{GPa})$, while the wEDM-CH $(0.7 \mathrm{GPa})$ has less than the half.

To further elucidate the effect of the manufacturing process on the mechanical response of the samples, high strain-rate impact tests were performed in an effort to highlight the strain-rate sensitivity. The impact tester used has been presented in [15]. The impact speed 
was selected to $8 \mathrm{~m} / \mathrm{s}$. Figure 6 shows the stress-strain responses of the three samples under impact loadings, together with representative images of the sample after the impact. In the milled sample, after a steep increase of the stress to a value of $48 \mathrm{MPa}$, it fluctuates over a value $37 \mathrm{MPa}$. The wEDM-CH performs almost in the same way, having a fluctuation of the stress over a value of $37 \mathrm{GPa}$, without showing a maximum stress value at the beginning of the impact. The worst performance among the tested samples appeared in the case of the wEDM-Water, where the stress has continuously a decreasing tendency versus the strain. This behavior can be explained by the images of the samples after the impact. As shown in Fig. 6 the wEDM-Water sample is almost fully delaminated, indicating that these samples cannot withstand the impact load but break into smaller pieces due to the high strain rates. This is not the case for the milled and wEDM-CH samples, which present strain-rate hardening, reaching higher stresses than the ones in the quasi-static test, as a consequence of a more cohesive material. The brittle nature and the tendency to delaminate of the wEDM-Water sample can be attributed to Hydrogen embrittlement, due to the aqueous nature of the working fluid.
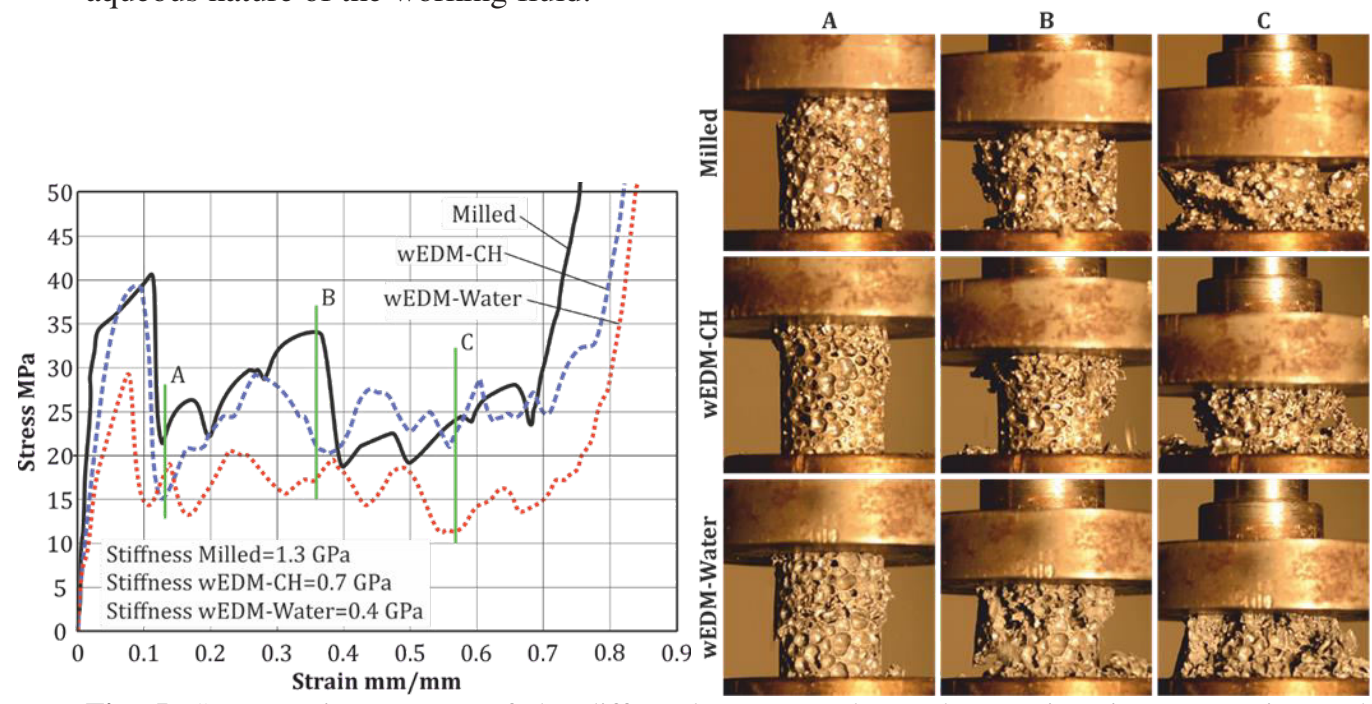

Fig. 5. Stress-strain response of the differently cut samples under quasi-static compression and characteristic pictures of the deformed samples at various strains.

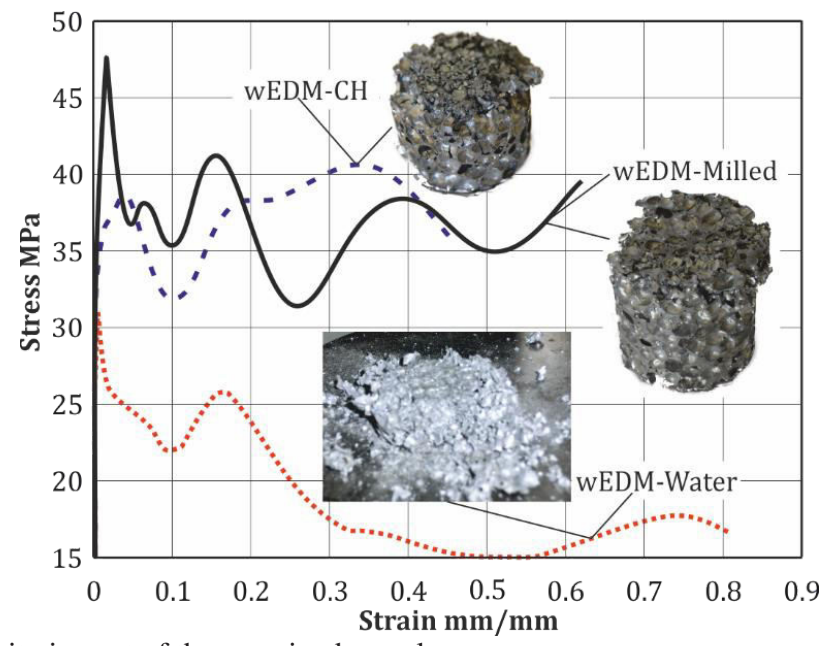

Fig. 6. High velocity impact of the examined samples. 


\section{Conclusions}

In the present study, closed-cell aluminum foams were produced and processed by milling and wire-EDM in CH- and Water-based working fluids. After an optimization loop, to select the cutting conditions leading to a good machinability, cylindrical samples were manufactured. Macro- and micro-structural analysis and mechanical testing were employed to assess the functional properties of the machined porous $\mathrm{Al}$, as well as to elucidate the mechanisms leading to differentiation of properties according to the manufacturing process. The wEDM-Water samples seem to be affected by the process, as their surface (derived by macro- and micro-scale characterization) is severely affected by the process, presenting high degree of opened cells, white layer formation and low mechanical properties, possibly due to an additional factor, the Hydrogen embrittlement. In this case, the sample delaminates, especially at higher strain rates. A promising result in terms of the aforementioned factors appears in the case of wEDM-CH, which may offer an almost distortion-free surface and mechanical properties close to the milled samples.

\section{References}

1. J. Schoop, F. Ambrosy, F. Zanger, V. Schulze, T.J. Balk, I.S. Jawahir, J. Mater. Process. Tech. 229, 614 (2016).

2. N. Michailidis, S. Kombogiannis, P. Charalampous, G. Maliaris, F. Stergioudi, CIRP Ann.-Manuf. Techn. 66, 121 (2017).

3. J.C. Aurich, D.Dornfeld, P.J. Arrazola, V. Franke, L. Leitz, S. Min, CIRP Ann.-Manuf. Techn. 58, 519 (2009).

4. A.M. Matz, D. Kammerer, N. Jost, K. Oßwald, Procedia CIRP 42, 263 (2016).

5. M. De Giorgi, S. Giancane, R. Nobile, F. Palano, EPJ Web of Conferences 6, Art. 31004 (2010).

6. D. R. Cluff, S. Esmaeili, J. Mater. Sci. Technol. 43, 1121 (2008).

7. W.I. Clark, A.J. Shih, R.L. Lemaster, S.B. McSpadden, Int. J. Mach. Tool Manu. 43, 533 (2003).

8. H. Qiao, S. Basu, C. Saldana, Procedia CIRP 45, 335 (2016).

9. R. Zou, Z. Yu, W. Li, M. Guo, J. Li, J. Mater. Process. Tech. 232, 43 (2016).

10. K. Wang, Q. Zhang, Q. Liu, G. Zhu, J. Zhang, Int. J. Adv. Manuf. Technol. 90, 2589 (2017).

11. N. Michailidis, E. Smyrnaios, G. Maliaris, F. Stergioudi, A. Tsouknidas, Adv. Eng. Mater. 16, 289 (2014).

12. F. Klocke, W. König, Fertigungsverfahren 3: Abtragen, Generieren und Lasermaterialbearbeitung, Springer. ISBN 3-540-23492-6 (2007).

13. M. Kunieda, B. Lauwers, K.P. Rajurkar, B.M. Schumacher, CIRP Ann.-Manuf. Techn. 54, 64 (2005).

14. F. Klocke, L. Hensgen, A. Klink, L. Ehle, A. Schwedt, Procedia CIRP 42, 673 (2016).

15. N. Michailidis, Mat. Scie. Eng. A 528, 4204 (2011). 